\title{
1 A data-driven approach for characterizing community scale air pollution exposure 2 disparities in inland Southern California
}

3 Khanh Do ${ }^{1,2}$, Haofei $\mathrm{Yu}^{3}$, Jasmin Velasquez ${ }^{1,2}$, Marilyn Grell-Brisk ${ }^{2}$, Heather $\mathrm{Smith}^{4}$, Cesunica E.

$4 \quad$ Ivey $^{1,2, *}$

$5{ }^{1}$ Department of Chemical and Environmental Engineering, University of California, Riverside, 6 Riverside, CA

$7 \quad{ }^{2}$ Center for Environmental Research and Technology, Riverside, CA

$8{ }^{3}$ Department of Civil, Environmental and Construction Engineering, University of Central Florida, 9 Orlando, FL

$10 \quad{ }^{4}$ Life Sciences Department, Riverside City College, Riverside, CA

12 *Corresponding Author: cesunica@ucr.edu, 1084 Columbia Avenue, Riverside CA 92507

15 This publication is currently under review in Journal of Aerosol Science, and a decision has not 16 been made on its acceptance. Subsequent versions of this manuscript may have slightly different 17 content. If accepted, the final version of this manuscript will be available via the 'Peer-reviewed 18 Publication DOI' link on the right-hand side of this page. Please feel free to contact the 19 corresponding author with feedback and suggestions. 
Highlights

- Wearable monitors enable high temporal resolution analysis of personal exposure

- Microenvironments were identified by GIS-based spatial clustering of measurements

- Most vulnerable community had highest observed personal-ambient ratios in the home

- High variability in personal $\mathrm{PM}_{2.5}$ despite low variability in ambient $\mathrm{PM}_{2.5}$

\section{Abstract}

In 2017, Assembly Bill 617 was approved in state of California, which mandated the allocation of resources for addressing air pollutant exposure disparities in underserved communities across the state. The bill stipulated the implementation of community scale monitoring and the development of local emissions reductions plans. We aimed to develop a streamlined, robust, and accessible $\mathrm{PM}_{2.5}$ exposure assessment approach to support environmental justice analyses. We sought to characterize individual $\mathrm{PM}_{2.5}$ exposure over multiple 24-hr periods in the inland Southern California region, which includes the underserved community of San Bernardino, CA. Personal sampling took place over five weeks in Spring of 2019, and personal $\mathrm{PM}_{2.5}$ exposure was monitored for 18 adult participants for multiple, consecutive 24-hr periods. Exposure and location data were available at five-second resolution, and participant data recovery was $50.8 \%$ on average. A spatial clustering algorithm was used to classify data points as one of seven microenvironments. Mean and median personal-ambient $\mathrm{PM}_{2.5}$ ratios were aggregated along SES lines for eligible datasets. GIS-based spatial clustering facilitated efficient microenvironment classification for more than 920,000 data points. Mean (median) personal-ambient ratios ranged from $0.02(0.00)$ to $3.49(0.55)$ for each microenvironment when aggregated along SES-lines. Aggregated ratios indicated that participants from the lowest SES community experienced higher home exposures

42 compared to participants of all other communities over consecutive 24-hr monitoring periods, 43 despite high participant mobility and relatively low variability in ambient $\mathrm{PM}_{2.5}$ during the study.

44 The methods described here highlight the robust and accessible nature of the personal sampling 45 campaign, which was specifically designed to reduce participant fatigue and engage members of 46 the inland Southern California community who may experience barriers when engaging with the 47 scientific community. This approach is promising for larger-scale, community-focused, personal 48 exposure campaigns for direct and accurate analysis of environmental justice. 
49 Keywords: particulate matter; wearable monitors; personal exposure; environmental justice

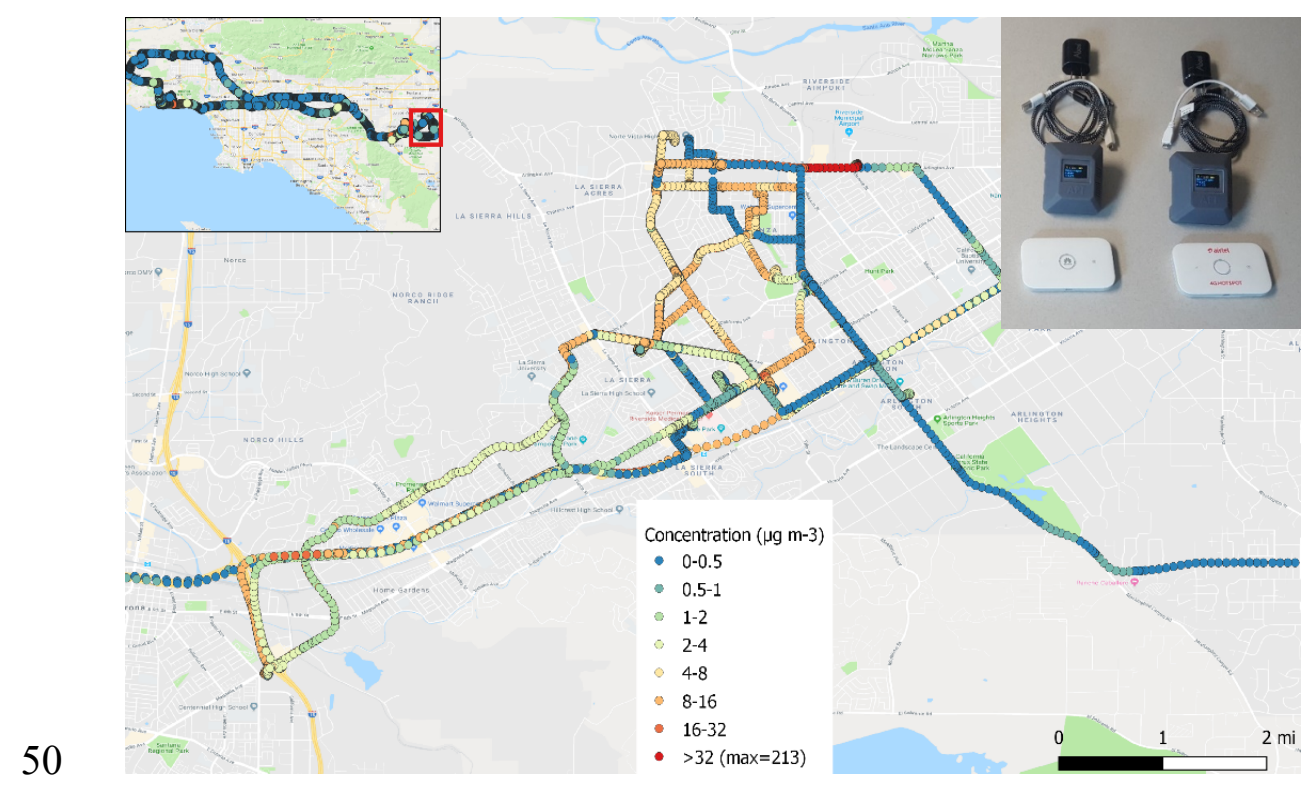




\section{Introduction}

53 Ambient particulate matter (PM) has been widely studied, and researchers have carefully examined

54 the impact of PM exposure on human health. Many air monitoring stations are operated in the U.S.

55 to measure the trends and composition of ambient PM in support of the National Ambient Air

56 Quality Standards (NAAQS). However, ambient PM concentrations may not reflect actual daily

57 personal exposure (PE) (Koistinen et al., 2004). Further the sparseness of the monitoring network

58 leads to low spatial resolution data and necessitates gap-filling, which affects the accuracy of PM

59 exposure assessments that are based on ambient measurements (X. Yu et al., 2019).

60 People spend most of their time indoors (approximately 85-90\%) and are most frequently exposed

61 to indoor pollutants(Long et al., 2001). Home and workplace are the two most dominant indoor

62 microenvironments. Indoor PM originates from cooking, smoking, cleaning products, vacuuming,

63 and dusting; while in offices, PM is emitted from printing, mechanical grinding, consumer

64 products, and dusting. The Environmental Protection Agency (EPA) carried out the particulate

65 total exposure assessment methodology (PTEAM) study on 178 non-smoking randomly selected

66 homes in Riverside, CA. The study showed that indoor $\mathrm{PM}_{2.5}(\mathrm{PM}$ with an aerodynamic diameter

67 less than or equal to $2.5 \mu \mathrm{m}$ ) levels were slightly lower than outdoor levels during the day.

68 However, at night the differences were significant (Clayton et al., 1993; Özkaynak et al., 1996;

69 Thomas et al., 1993). Although ambient $\mathrm{PM}_{2.5}$ penetrates into indoor environments, individual

70 behaviors and living conditions are found to be the most important factors that affect indoor

71 concentrations of PM (Kulmala et al., 1999; Long et al., 2001; Wallace, 1996).

72 Further, human mobility must also be taken into account for accurate exposure assessment. Yu et

73 al. compared call detail record and home-based methods to estimate biases in exposure methods.

74 The study showed that the home-based method both over- and under-estimates air pollutant

75 exposure levels (H. Yu et al., 2018). In addition, many studies have used outputs from chemical

76 transport models to verify the misclassification when using central monitor concentrations (CMC)

77 to represent the exposure near the monitoring sites. Hu et al. showed that the population weighted

78 concentrations of primary $\mathrm{PM}_{2.5}$ of the model differ from the $\mathrm{CMC}$ values by -40 to $+60 \%$. The

79 misclassification could be significant when assuming the same representative distance across

80 central monitoring sites for multiple pollutants in a large-scale, spatial and temporal epidemiology

81 studies (Hu et al., 2019). 
82 Advancements in low-cost environmental sensing technologies have enabled the development of 83 small, portable, and relatively precise PM sensors for personal exposure assessment. In a recent 84 study by Quinn et al., filter-based, wearable, automated microenvironmental aerosol samplers 85 (AMAS) were used to conduct a personal exposure study with 37 high school students from 25 86 high schools in Fresno, CA (Quinn et al., 2018). The wearable AMAS enabled the measurement 87 of black carbon and oxidative potential in targeted microenvironments, but the measurements were 88 coarsely-resolved in time. Further, low-cost optical PM sensors have very high sampling 89 frequencies, and low-cost sensing measurements are moderately accurate (Feenstra et al., 2019). 90 The Plantower PMS (v. 1003/3003) is a commonly used optical sensor, and has a correlation 91 coefficient of 0.88 with the federal reference method (FRM), which reflects the viability of the 92 sensor for exposure measurements (Kelly et al., 2017). Combined with Internet of Things (IoT) 93 technology, the Plantower PMS can be further integrated to deliver more functionalities to end 94 users. Data collected from a low-cost sensing device or IoT network can be uploaded to the cloud 95 and made available in near-real-time to users. Despite of all the conveniences of low-cost sensing, 96 there are still room for improvements of PM sensor accuracy. Sensors require consistent 97 calibration, and the measurements may require additional post-processing (Zheng et al., 2018).

98 In this paper, we detail a pilot-scale personal exposure campaign using wearable $\mathrm{PM}_{2.5}$ sensors 99 with real-time, remote monitoring capability. Our study engaged residents of five inland Southern 100 California cities and captured spatial and temporal variability of $\mathrm{PM}_{2.5}$ exposures over multiple, 101 consecutive 24-hour periods. The main objective of this pilot study was to develop and implement 102 a high-resolution monitoring and analysis framework for characterizing $\mathrm{PM}_{2.5}$ exposure variability 103 for individuals from different cities of residence and subsequently different socioeconomic status 104 (SES) neighborhoods. As Southern California historically has high ambient $\mathrm{PM}_{2.5}$ levels, we 105 sought to understand which microenvironments posed the greatest exposure risk in the region. Our 106 study elucidates the behavior-dependent patterns of $\mathrm{PM}_{2.5}$ exposure in a high-traffic, industrialized 107 region of Southern California.

108 2. Materials and Methods

109

\subsection{Study Area}


110 Our personal exposure study was conducted in inland Southern California, better known as the

111 Inland Empire, covering an area of approximately 200 square miles (Figure S1). More specifically,

112 the study area includes the cities of Moreno Valley (2018 U.S. Census population of 209,050),

113 Redlands (71,596), Riverside (330,063), San Bernardino (215,941), and Yucaipa (53,682), CA

114 (Table S1). In 2018, median household income estimates were \$63,572, \$72,523, \$65,313,

$115 \$ 43,136$, and $\$ 63,657$; and poverty rates were $19.9 \%, 13.6 \%, 15.6 \%, 28.4 \%$, and $12.3 \%$,

116 respectively (U.S. Census Bureau). The major routes that service these cities include interstate

117 routes 10,15 , and 215, and U.S. highways $60,66,91$, and 210 . The major air pollution sources in

118 inland Southern California are on-road traffic, off-road mobile sources (e.g., railyard equipment),

119 industrial point sources (e.g., cement manufacturing and power generating facilities), and smaller

120 point sources (e.g., auto body shops, residential combustion, and restaurants). In recent years, the

121 logistics industry has expanded in the region, prompting the construction of large warehouses that

122 rely on heavy-duty vehicles for goods transport.

123 The recently implemented California Assembly Bill 617 was designed partially to address 124 disproportionate impacts of air pollution in environmental justice communities, and San 125 Bernardino was selected as a Phase 1 community in 2018 (Garcia, 2017). Previous studies have 126 highlighted health disparities in the San Bernardino community due to its proximity to a large 127 railyard (Spencer-Hwang et al., 2015, 2016). Through our study, we sought to understand personal 128 exposure patterns as they relate to the unique environmental and socioeconomic characteristics of 129 inland Southern California.

$130 \quad$ 2.2 Sampling Campaign

131 For the sampling campaign, we recruited 18 adult participants (18 years and older; 61\% males; $13255 \%$ Latinx) with varied occupations (50\% identified as college students). All sampling activities 133 and interactions with participants were pre-approved by the University of California, Riverside 134 Institutional Review Board (protocol number: HS 18-206). The overall campaign took place over 135 a five-week period from 03-10-2019 to 04-14-2019. Each week on Sunday, we distributed a PM 136 monitoring pack to four participants, except for the first week which had two participants (Figure 137 1). Participants kept the packs for a duration of seven days, allowing the assessment of inter- and 138 intra-day exposure variability for each individual. 

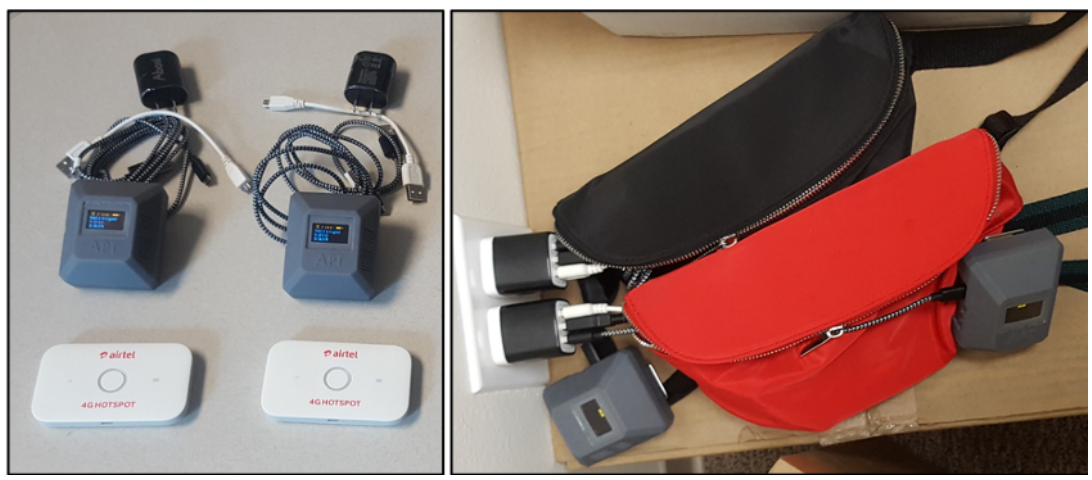

141 Figure 1. (Left) Wearable particulate matter monitors from Applied Particle Technology (St. Louis, MO).

142 Data were transmitted via Wi-Fi hotspots and were accessible online in real-time. (Right) PM sampling 143 pack used in the personal exposure study. The monitors were clipped outside of the pack, and the Wi-Fi 144 and GPS data loggers were housed inside of the pack.

145 We tracked participant locations with GPS data loggers. Participants were required to carry the 146 packs during the day, and packs were placed in their bedroom or living spaces at night. After the 147 seven-day deployment, the packs were returned to our research facility. We retrieved and removed 148 the GPS data from the data loggers before the next deployment for privacy. One participant's GPS 149 data were missing, so this dataset was removed, and subsequent analyses were carried out for 17 150 datasets. The participant breakdown by city was the following: two from Moreno Valley, two from 151 Redlands, five from Riverside, six from San Bernardino, and two from Yucaipa. We recognize the 152 uncertainty introduced by the sample size and city breakdown. However, our pilot study generated 153 useful insights that will be leveraged during our larger phase two sampling campaign.

\subsection{Monitoring Equipment}

155 Each monitoring pack (total $=4$ ) included a battery-powered PM monitor, a GlobalSat-DG-500 156 (New Taipei City, Taiwan) GPS module, a Huawei Wi-Fi hotspot, Elitech temperature log, and 157 necessary accessories. The PM monitors are developed by Applied Particle Technology (APT, St. 158 Louis, Missouri, USA) and utilize the Plantower PMS optical sensor (Figure 1). The monitors are 159 commercially available, and our research team was not directly involved with monitor 160 development. The dimensions of the PM monitors are 2 in. $x 1$ in. $x 2.25$ in. ( $\mathrm{L} \times \mathrm{W} \times \mathrm{H}$ ). The 161 APT monitor provided four $\mathrm{PM}_{1}, \mathrm{PM}_{2.5}$, and $\mathrm{PM}_{10}$ measurements per minute, but we only analyzed 
$162 \mathrm{PM}_{2.5}$ measurements due to the extensive literature and relevance of $\mathrm{PM}_{2.5}$ exposure and health, 163 and due to the availability of suitable reference measurements for monitor evaluation. The APT 164 monitors also provide measurements of relative humidity and temperature, and the data are 165 uploaded in real-time via the mobile hotspot to the vendor-hosted web interface. The size, 166 simplicity, mobility, and accessibility of the APT device was ideal for community engagement.

167 The sampling rate of the PM monitor was once every 15 seconds, totaling a maximum of 168 approximately 40,320 possible measurements at the end of the seven-day sampling period, plus or 169 minus a few hours of measurements depending on the scheduled pick-up and drop-off times.

\subsection{Data Processing}

171 Although a uniform usage protocol was established for the study, datasets had varying degrees of 172 availability due to the operating habits of the participants. We assigned all missing PM 173 measurements as "-9999", then PM data were synced with the GPS data by their dates and

174 timestamps. Since the GPS data logger's sampling rate was once every five seconds, we performed 175 a linear interpolation on the PM data from 15 to five second intervals to obtain the highest 176 resolution for our datasets. The resulting combined datasets provide the date, time of day, $\mathrm{PM}_{2.5}$ 177 concentrations, relative humidity, temperature, and the corresponding latitude and longitude. As a 178 note, the GPS position was intermittently measured at times because the data logger stopped 179 recording if the no movement was detected after 30 seconds. To account for the idling periods, we 180 assigned the previous latitude and longitude to the missing timestamp if the distance between the 181 two intervals was less than 20 meters (Figure S2). When the distance was greater than 20 meters 182 and less than or equal 50 meters, we performed linear interpolation between the two points. A 183 distance greater than 50 meters was assigned "NaN" and considered an invalid data point due to 184 uncertainty in participant mobility during the idle period. The five-second syncing lends a 185 maximum of approximately 120,960 possible data points for each participant.

\subsection{Co-location and Adjustments}

187 We co-located the personal PM monitors at the Mira Loma Van Buren (MLVB, AQS ID: 188 060658005) air monitoring site to evaluate the hourly performance of the monitors. We housed 189 the wearable monitors in a home-built enclosure and positioned the enclosure near the site's federal 190 equivalent method (FEM) PM $_{2.5}$ samplers. The enclosure was built using steel mesh panels to 8 
191 maximize the air flow over the monitors. The monitors were kept on-site for two weeks, and we

192 continuously monitored the activities of each sensor through the web server to ensure that each

193 device was operating optimally. At the end of the co-location period, we obtained $\mathrm{PM}_{2.5}$ reference

194 data for the performance analysis. For our study, we used polynomial fitting to adjust the raw data

195 to the FEM reference data. Our measurements were determined to be uninfluenced by relative

196 humidity and temperature, hence the polynomial fittings were solely based on two parameters:

197 reference measurements and raw measurements (Note S1). The fitting method is well described in

198 a paper by Zheng et al. (Zheng et al., 2018). We also explored one other approach to adjust the

199 raw data, for which we utilized using machine learning with random forest regression (RFR) to

200 construct a pattern-based relationship between the reference and raw data. See Note S2 for further

201 discussion of the calibration model testing.

$202 \quad 2.6$ Data Analysis

203 We classified microenvironments of all data points based on the GPS measurements. We used the

204 density-based spatial clustering of applications with noise (DBSCAN) algorithm in the QGIS

205 (https://www.qgis.org/) open source GIS platform, and DBSCAN clusters points based on a two-

206 dimensional implementation.(QGIS Development Team, 2019) We then defined each spatial

207 cluster by mandating a minimum size of $120 \mathrm{PM}_{2.5} / \mathrm{GPS}$ measurements within a maximum distance

208 of 0.0005 degrees ( $\sim 55$ meters). The clusters were manually evaluated and assigned a 209 microenvironment class and activity by overlaying the clusters onto Google Maps.

210 Microenvironment classes included home $(\mathrm{H})$, work (or university, W), restaurant (R), retail (RE),

211 leisure indoor (LI), leisure outdoor (LO), and transient (T); and microenvironment was classified

212 and assigned to the cluster based on the proximity of the cluster center to labels available in Google

213 Maps. The "transient" classification indicates that the speed measurement was greater than 10

214 kilometers per hour, regardless of prior cluster classification. The "unclassified" classification was

215 given to non-clustered, non-transient data points. We make no assumptions about participant 216 mobility within the microenvironment.

\section{$217 \quad 2.7$ Ambient PM2.5 Contour Fields}

218 We constructed a $\mathrm{PM}_{2.5}$ contour mesh over Southern California to compare the personal exposure 219 of $\mathrm{PM}_{2.5}$ to ambient $\mathrm{PM}_{2.5}$. Participant mobility varied, and measurement locations were up to 100 
220 miles away from the main study location. The input data for the ambient $\mathrm{PM}_{2.5}$ spatial fields were 221 accessed from the regulatory monitoring network of the South Coast Air Quality Management 222 District. To construct hourly contour fields, we performed cubic interpolation on hourly $\mathrm{PM}_{2.5}$ 223 measurements from 18 monitoring stations. Participant coordinates were paired to the 224 corresponding contour location, resulting in corresponding ambient and personal $\mathrm{PM}_{2.5}$ data points 225 for all participants.

\section{3. Results}

\section{$227 \quad 3.1$ Personal and Ambient Data Overview}

228 Calibration of PM monitors using the polynomial fittings resulted in good agreement between the 229 adjusted personal measurements and reference $\mathrm{PM}_{2.5}$ measurements. The mean bias for the four 230 monitors ranged from -0.11 to 0.61 , slopes ranged from 0.99 to 1.10 , intercepts ranged from 0.012 231 to 0.75 , and $\mathrm{R}^{2}$ ranged from $0.41-0.45$ (Note $\mathrm{S} 2$ ).

232 For interpolated personal measurements, we define data recovery as the percentage of five-second 233 data points available out of the total possible data points for each participant's sampling period 234 (range: $0.5-95.6 \%$ ). Mean data recovery was $50.8 \%$, corresponding to 54,120 valid data points 235 per participant; and median data recovery was $51.8 \%$, corresponding to 53,921valid data points 236 per participant (Table S2). In comparison to prior studies our approach was successful in collecting 237 an exceptionally large amount of data, where valid personal data points from all 17 participants 238 totaled 920,045 (Bekö et al., 2015; Li et al., 2017; Minet et al., 2018; Piedrahita et al., 2017; Quinn 239 et al., 2018; Thomas et al., 1993).

240 Personal $\mathrm{PM}_{2.5}$ measurements were compared to corresponding ambient $\mathrm{PM}_{2.5}$ measurement, and 241 ambient data were extracted from contours of hourly measurements from regulatory monitoring 242 stations (Figure S3). Median ambient $\mathrm{PM}_{2.5}$ concentrations for each sampling week ranged from 2434.4 to $10.2 \mu \mathrm{g} \mathrm{m}^{-3}$, and maximum concentrations ranged from 22.3 to $28.2 \mu \mathrm{g} \mathrm{m}^{-3}$ (Figure 2). 244 Ambient $\mathrm{PM}_{2.5}$ concentrations are lowest in the spring season in southern California. 


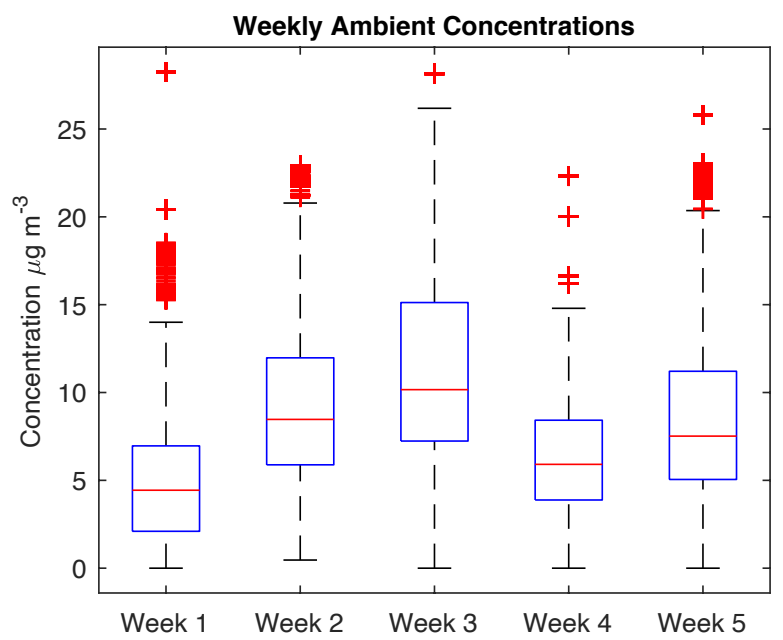

246 Figure 2. Distributions of ambient $\mathrm{PM}_{2.5}$ concentrations $\left(\mu \mathrm{g} \mathrm{m}^{-3}\right)$ corresponding to participant locations

247 during each week of the study. Median concentrations were 4.4, 8.5, 10.2, 5.9, and 7.5, for weeks 1-5, 248 respectively.

\subsection{Exposure and Activity}

250 Time series of individual personal exposure measurements identify acute $\mathrm{PM}_{2.5}$ exposure episodes

251 (less than one hour, $>35 \mu \mathrm{g} \mathrm{m}^{-3}$ ), and acute exposures were highly variable for all participants.

252 We highlight time series of consecutive, 24-hour personal measurements at 5-seconds resolution

253 along with the corresponding ambient hourly measurement for four participants. Maximum acute

254 exposures ranged from approximately 70 (Redlands) to 2500 (Moreno Valley) $\mu \mathrm{g} \mathrm{m}^{-3}$, further 255 justifying the need for individual level analysis of exposure risk (Figure 3). Participant 2 (San 256 Bernardino) experienced the highest exposures in the home microenvironment in the late 257 afternoons and early evening, as well as in an indoor residential microenvironment that was not 258 classified as home. Participant 5 (Redlands) experienced all acute episodes in the work/university 259 microenvironment, and the residential location university housing. Participant 5 exposures were 260 not as severe as the other highlighted exposures.

261 Participant 13 (Moreno Valley) experienced frequent, extreme exposures with consistently high 262 measurements greater than $500 \mathrm{~g} \mathrm{~m}^{-3}$ in the home and leisure indoor microenvironments. High 263 measurements were observed in short intervals in the restaurant microenvironments, specifically 264 a popular burger and coffee chain. High measurements were also infrequently observed in the 
265 transient and work microenvironments. Based on the short duration $(<10$ minutes $)$ of the extreme 266 exposures and the occurrence in the majority of microenvironments, it is suspected that the 267 participant is a smoker. Participant 15 (Riverside) experienced exposures greater than $100 \mu \mathrm{g} \mathrm{m}^{-3}$ 268 in the home microenvironment, and consistently elevated $\mathrm{PM}_{2.5}$ was observed during time spent 269 in a restaurant microenvironment (range 20-50 $\mu \mathrm{g} \mathrm{m}^{-3}$ ). Time series for all participants can be 270 found in Note S3 in the Supplementary Material.
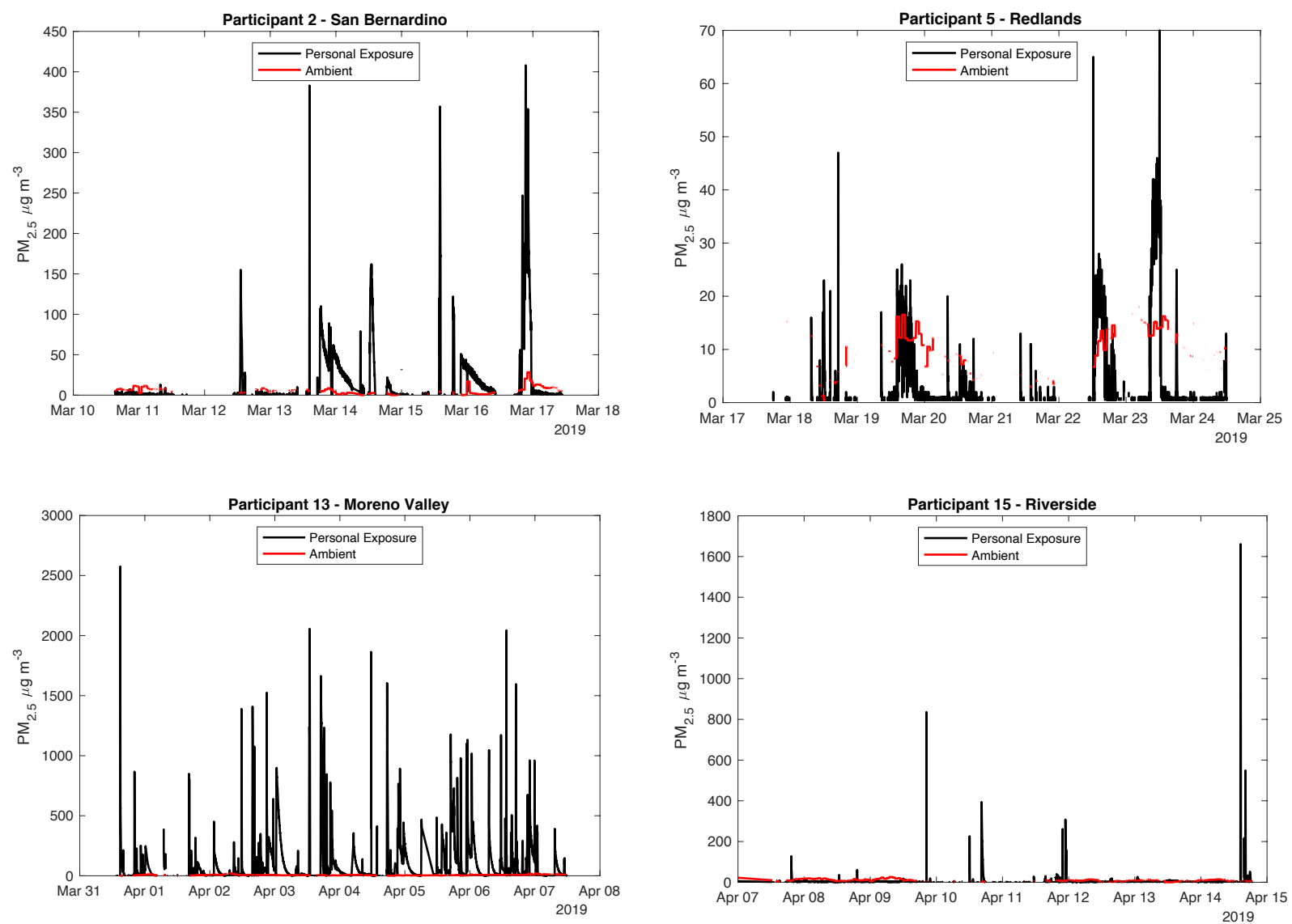

272 Figure 3. Sample time series of 5-second personal (black) and hourly ambient (red) monitoring data for 273 four participants from San Bernardino (top-left), Redlands (top-right), Moreno Valley (bottom-left), and 274 Riverside (bottom-right). 
276 Personal and ambient $\mathrm{PM}_{2.5}$ data were aggregated for cities with two or more participants with $27750 \%$ or greater data recovery, which was the criteria for inclusion in the inter-city analysis (Table 278 1). Results from those participants were then stratified along SES lines: Redlands/Riverside $(\mathrm{N}=$ 279 5, high SES) and San Bernardino ( $\mathrm{N}=4$, low SES); there were no datasets from Moreno Valley 280 and Yucaipa that met the aggregation criteria. Average data recovery for these participants was $28173 \%$ (Redlands/Riverside) and 72\% (San Bernardino). Aggregated median ambient concentrations 282 were consistently higher than median personal concentrations, and the highest median personal 283 concentrations were observed in home microenvironment for both SES groups. San Bernardino 284 personal medians in the home microenvironment were higher despite having slightly lower 285 ambient medians than Redlands/Riverside. Short-term personal exposures were higher than $20 \mu \mathrm{g}$ $286 \mathrm{~m}^{-3}$ in work, university, restaurant, retail, leisure indoor, and transient microenvironments for 287 aggregated datasets (Figure 4).

288 Table 1. Summary of the total number of valid data points, average data recovery, and median personal 289 (ambient) $\mathrm{PM}_{2.5}$ concentrations $\left(\mu \mathrm{g} \mathrm{m}^{-3}\right)$ for Redlands and Riverside $(\mathrm{N}=5)$, and San Bernardino $(\mathrm{N}=4)$ 290 participants with data recovery greater than $50 \%$.

\begin{tabular}{|l|l|l|}
\hline City & Redlands and Riverside & San Bernardino \\
\hline $\begin{array}{l}\text { Number of Data Points } \\
\text { (Average Data Recovery) }\end{array}$ & $387,781(73 \%)$ & $302,305(72 \%)$ \\
\hline Home & $1.67(8.66)$ & $5.33(7.69)$ \\
\hline Work or University & $0.00(8.91)$ & $0.00(3.85)$ \\
\hline Restaurant & $1.00(9.36)$ & $0.00(4.50)$ \\
\hline Retail & $1.00(8.64)$ & $0.00(7.48)$ \\
\hline Leisure Indoor & $0.00(11.3)$ & $2.00(6.52)$ \\
\hline Leisure Outdoor & $0.00(6.17)$ & $0.00(1.68)$ \\
\hline Transient & $1.00(7.49)$ & $0.00(9.79)$ \\
\hline Unclassified & $1.00(6.22)$ & $0.00(5.20)$ \\
\hline
\end{tabular}



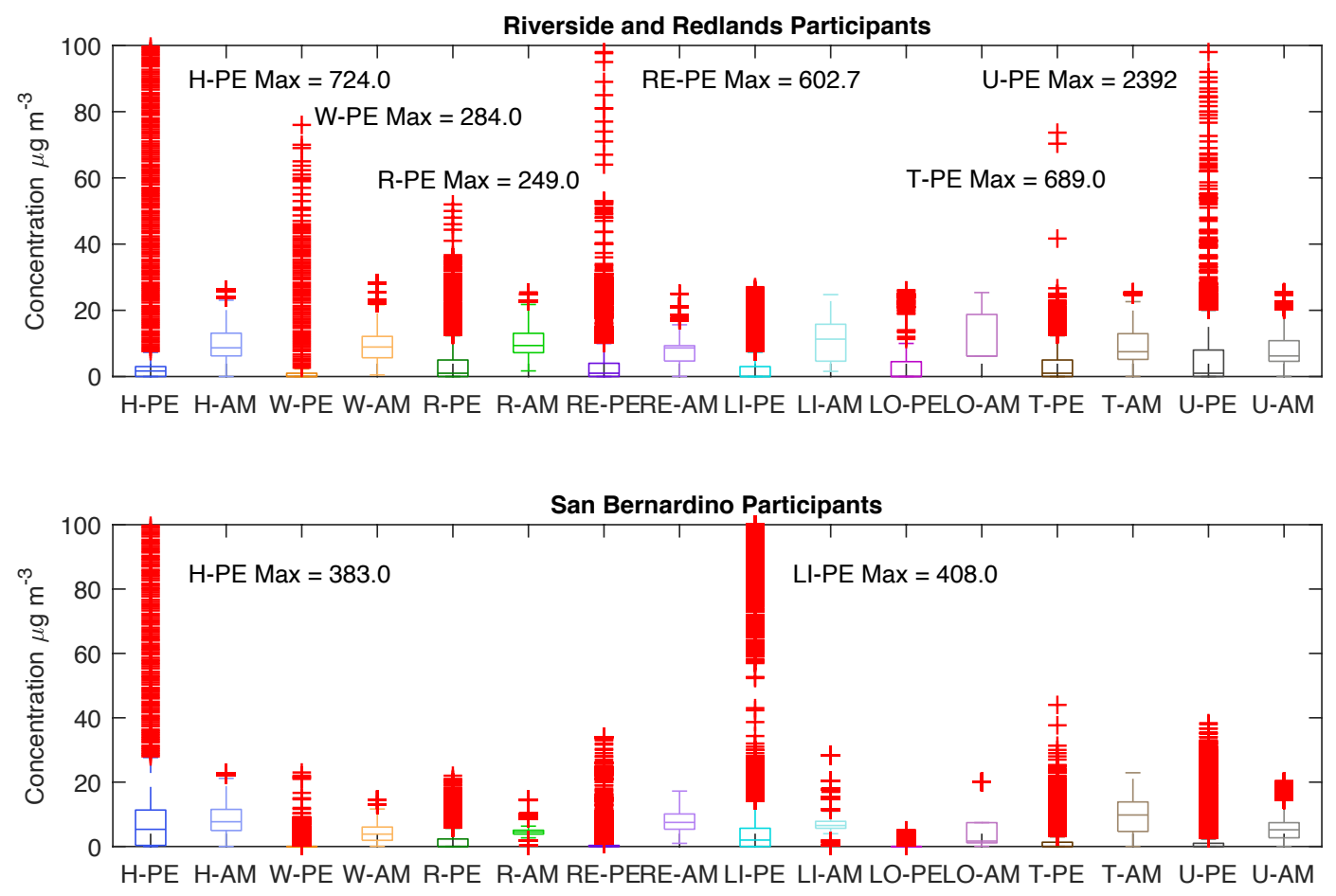

293 Figure 4. Distributions of personal and ambient $\mathrm{PM}_{2.5}$ measurements for Redlands and Riverside $(\mathrm{N}=5)$, 294 and San Bernardino ( $\mathrm{N}=4$ ) participants with data recovery greater than $50 \%$. The labels indicate the 295 microenvironment classifications: home $(\mathrm{H})$, work (or university, W), restaurant $(\mathrm{R})$, retail (RE), leisure 296 indoor (LI), leisure outdoor (LO), transient (T), and unclassified (U). Personal exposure measurements are 297 labeled “-PE," and ambient data are labeled as "-AM."

298 For SES-aggregated datasets, mean personal-ambient (P-A) ratios for each microenvironment 299 ranged from 0.02 to 3.49 , and median ratios ranged from 0.00 to 0.55 (Table 2). Higher mean ratios 300 compared to median ratios reflect the influence of the outliers in the personal measurements. Ratios 301 less than one indicate that personal environments had lower $\mathrm{PM}_{2.5}$ levels than those derived from 302 ambient data. For classified microenvironment clusters, the highest mean P-A ratios were observed 303 in the retail 1.45 (0.60, Redlands/Riverside) and home (3.49, San Bernardino) microenvironments 304 (Table 2). Redlands/Riverside had ratios greater than one for transient (1.17) and unclassified data 305 points (2.81), while the mean home ratio was 0.76. San Bernardino retail ratio was 2.47. The 306 highest median P-A ratios were observed in the home microenvironments for both 307 Redlands/Riverside (0.16) and San Bernardino (0.55) for classified clusters. Wilcoxon rank sum 
308 tests indicated significant $(\mathrm{p}<0.05)$ differences between non-outlier personal-ambient data pairs 309 for all microenvironments and for every participant with the exception of the leisure indoor and 310 restaurant microenvironments for Participants 5 and 8, respectively. Outlier personal data and 311 corresponding ambient data were excluded from the Wilcoxon tests. Mean and median ratios for 312 all participants can be found Tables S4 and S5 in the Supplementary Material.

313 Table 2. Mean (median) personal-ambient ratios by city of residence for Redlands and Riverside $(\mathrm{N}=5)$ 314 and San Bernardino $(\mathrm{N}=4)$ participants with data recovery greater than $50 \%$. Bold indicates higher personal $315 \quad \mathrm{PM}_{2.5}$ concentrations than the corresponding ambient concentrations.

\begin{tabular}{|l|l|l|}
\hline City & Redlands and Riverside & San Bernardino \\
\hline Home & $0.76(0.16)$ & $\mathbf{3 . 4 9}(0.55)$ \\
\hline Work or University & $0.30(0.00)$ & $0.06(0.00)$ \\
\hline Restaurant & $0.35(0.12)$ & $0.48(0.22)$ \\
\hline Retail & $1.45(0.15)$ & $0.09(0.00)$ \\
\hline Leisure Indoor & $0.28(0.00)$ & $\mathbf{2 . 4 7}(0.29)$ \\
\hline Leisure Outdoor & $0.22(0.00)$ & $0.02(0.00)$ \\
\hline Transient & $\mathbf{1 . 1 7}(0.08)$ & $0.14(0.00)$ \\
\hline Unclassified & $\mathbf{2 . 8 1}(0.21)$ & $0.23(0.00)$ \\
\hline
\end{tabular}

\section{Discussion}

318 The majority of data points were classified as home for the highlighted participants (mean: $65 \%$, 319 median: 69\%) (Table S2). This is slightly higher, but consistent with previous personal exposure 320 studies (Bekö et al., 2015; Hsu et al., 2020; Quinn et al., 2018). Data points were classified in these 321 microenvironments at an average of $31 \%$ (median: 16\%) of the time, therefore non-home 322 exposures may be significant in the long-term (Table S2). Transient $\mathrm{PM}_{2.5}$ measurements were 323 within range of a previous personal exposure study conducted in California (Ham et al., 2017). 324 Microenvironment distributions of personal and ambient measurements can be found in Note S4 325 in the Supplementary Material. 
326 Calculations of time spent in each microenvironment are impacted by data recovery, and charging 327 protocols were best adhered to in the home environments near a convenient supply of electricity.

328 There were compliance issues during sampling that affected data recovery, which is common in 329 human subjects research (Chenail, 2011; Mehra, 2001). Monitor mobility and real-time data 330 transfer of PM monitors enabled the high-resolution personal sampling of our study. However, 331 data collection was impeded when component batteries drained, although a charging schedule was 332 provided but not always adhered to. At times the hardware stalled, or data transfer was limited by 333 availability of Wi-Fi signal. Participant accidents with the monitors, while rare, also interrupted 334 sampling; minor damages to the protective casings were mended before redeployment.

335 Our monitoring approach intuitively identifies participants that may be actively or passively 336 exposed to cigarette or vaping smoke, as very high personal measurements $\left(>100 \mu \mathrm{g} \mathrm{m}^{-3}\right)$ are 337 classified as outliers in a five-second resolution dataset (Figure 4) (Götschi et al., 2002; Koistinen 338 et al., 2004; Salmon et al., 2018; Slezakova et al., 2009). Suspected smoking events occur at 339 relatively shorter time scales throughout the day and are easily identified in the time series and 340 boxplots of personal measurements. Consequently, median P-A ratios derived from high temporal 341 resolution data are useful for evaluating non-smoking related $\mathrm{PM}_{2.5}$ exposures when smoking 342 status is undisclosed. Therefore, when comparing the bulk (non-outliers) of personal and ambient 343 measurements for Redlands/Riverside microenvironments, personal $\mathrm{PM}_{2.5}$ measurements are 344 much less than ambient $\mathrm{PM}_{2.5}$. Conversely, the San Bernardino median home microenvironment 345 exposure was most similar to the corresponding median ambient exposure (Table 1).

346 Considering the relatively small number of participants in the study, definitive generalizations 347 cannot be made regarding influences of residential location. However, the large amount of 348 measurements analyzed here provides a preliminary, yet robust, investigation of exposure 349 disparities. San Bernardino (highest poverty rates, lowest median household income) participants 350 with greater than $50 \%$ data recovery experienced higher home exposures compared with 351 participants from other cities. Redlands/Riverside (second/third lowest poverty rate, 352 highest/second-highest household incomes) participants overall had lower home personal 353 exposures and experienced higher personal exposures outside of the home. Since most time was 354 spent in the home microenvironment for the majority of participants, San Bernardino participants 355 were more likely to be exposed to higher $\mathrm{PM}_{2.5}$ concentrations, even when taking into account the 16 
356 high degree of mobility of participants which is reflected in the diversity of classified 357 microenvironments.

\section{Conclusions}

359 Our pilot study highlights the variability in community-scale exposure in a socioeconomically

360 diverse air basin that is heavily burdened by air pollution. A novel spatial clustering approach was 361 applied to classify the microenvironments of more than 900,000 high temporal resolution personal 362 exposure data points. Results from the study indicate that participants from the lowest 363 socioeconomic status community experienced overall higher personal exposures over consecutive 364 24-hr monitoring periods, despite high participant mobility and low variability in ambient $\mathrm{PM}_{2.5}$ 365 during the study. Our inclusive monitoring protocol minimizes participant fatigue and is well366 suited for real-time, long-term characterization of $\mathrm{PM}_{2.5}$ exposure disparities in underserved 367 communities. $\mathrm{PM}_{2.5}$ serves as a useful surrogate species for many other air pollutants that may 368 influence disproportionate exposures. The application of our streamlined, data-driven methods in 369 a larger-scale exposure study will further elucidate personal exposure disparities along racial and 370 socioeconomic lines.

\section{Data Availability}

372 In accordance with the University of California, Riverside Institutional Review Board, personal 373 data may only be distributed in an aggregated form to preserve participant privacy. All aggregated 374 and anonymized data are summarized in the Supplementary Material.

\section{Vitae}

\begin{tabular}{|l|l|}
\hline Khanh Do & $\begin{array}{l}\text { Ph.D. Candidate in the Chemical and Environmental } \\
\text { Engineering graduate program at UC Riverside. }\end{array}$ \\
\hline Haofei Yu & $\begin{array}{l}\text { Assistant Professor of Civil, Environmental and Construction } \\
\text { Engineering, specializing in air quality modeling, air pollution } \\
\text { sensor development, and health impacts studies. }\end{array}$ \\
\hline
\end{tabular}




\begin{tabular}{|l|l|}
\hline $\begin{array}{l}\text { Jasmin } \\
\text { Velasquez }\end{array}$ & $\begin{array}{l}\text { Undergraduate research assistant in the Chemical and } \\
\text { Environmental Engineering Department at UC Riverside. }\end{array}$ \\
\hline $\begin{array}{l}\text { Marilyn } \\
\text { Grell- } \\
\text { Brisk }\end{array}$ & $\begin{array}{l}\text { Assistant research scientist of environmental sociology at the } \\
\text { Center for Environmental Research and Technology, } \\
\text { specializing in macro-comparative quantitative research } \\
\text { methods. }\end{array}$ \\
$\begin{array}{l}\text { Heather } \\
\text { Smith }\end{array}$ & $\begin{array}{l}\text { Director of Life Sciences at Riverside City College, } \\
\text { specializing in environmental toxicology. }\end{array}$ \\
\hline $\begin{array}{l}\text { Cesunica } \\
\text { E. Ivey }\end{array}$ & $\begin{array}{l}\text { Assistant Professor of Chemical and Environmental } \\
\text { Engineering, specializing in air quality modeling, exposure } \\
\text { monitoring, and environmental justice. }\end{array}$ \\
\hline
\end{tabular}

377 Acknowledgements

378 We acknowledge Aaron Garcia, Saray Rodriguez, Hector Soto, Priscilla Villegas, and David 379 Wilson for their assistance with the field data collection. We thank Chela Larios of Center for

380 Community Action and Environmental Justice and Yassi Kavezade of Sierra Club for their help 381 with recruiting participants. We thank Jiaxi Fang and Tandeep Chadha of Applied Particle 382 Technology for their technical assistance, and Brandon Feenstra and Nelson Marquez for 383 facilitating co-location at the Mira Loma Van Buren air monitoring site.

\section{Funding}

385 This work was supported by the Alfred P. Sloan Foundation and Social Science Research Council. 


\section{References}

387 Bekö, G., Kjeldsen, B. U., Olsen, Y., Schipperijn, J., Wierzbicka, A., Karottki, D. G., Toftum, J., Loft, S., \& Clausen, G. (2015). Contribution of various microenvironments to the daily personal exposure to ultrafine particles: Personal monitoring coupled with GPS tracking. Atmospheric Environment, 110, 122-129. https://doi.org/10.1016/j.atmosenv.2015.03.053

Chenail, R. J. (2011). Interviewing the investigator: Strategies for addressing instrumentation and researcher bias concerns in qualitative research. Qualitative Report, 16(1), 255-262.

Clayton, C. A., Perritt, R. L., Pellizzari, E. D., Thomas, K. W., Whitmore, R. W., Wallace, L. A., Ozkaynak, H., \& Spengler, J. D. (1993). Particle Total Exposure Assessment Methodology (PTEAM) study: Distributions of aerosol and elemental concentrations in personal, indoor, and outdoor air samples in a southern California community. Journal of Exposure Analysis

Feenstra, B., Papapostolou, V., Hasheminassab, S., Zhang, H., Boghossian, B. Der, Cocker, D., \& 399 and Environmental Epidemiology, 3(2), 227-250.

Garcia, C. (2017). Assembly Bill No. 617. California State Assembly.

403 Götschi, T., Oglesby, L., Mathys, P., Monn, C., Manalis, N., Koistinen, K., Jantunen, M., 404 Hänninen, O., Polanska, L., \& Künzli, N. (2002). Comparison of Black Smoke and PM 2.5 Levels in Indoor and Outdoor Environments of Four European Cities. Environmental Science \& Technology, 36(6), 1191-1197. https://doi.org/10.1021/es010079n 
Ham, W., Vijayan, A., Schulte, N., \& Herner, J. D. (2017). Commuter exposure to PM2.5, BC, and UFP in six common transport microenvironments in Sacramento, California. Atmospheric Environment, 167, 335-345. https://doi.org/10.1016/j.atmosenv.2017.08.024

Hsu, W.-T., Chen, J.-L., Candice Lung, S.-C., \& Chen, Y.-C. (2020). PM2.5 exposure of various microenvironments in a community: Characteristics and applications. Environmental Pollution, 263, 114522. https://doi.org/10.1016/j.envpol.2020.114522

Hu, J., Ostro, B., Zhang, H., Ying, Q., \& Kleeman, M. J. (2019). Using Chemical Transport Model Predictions To Improve Exposure Assessment of PM 2.5 Constituents. Environmental Science \& Technology Letters, 6(8), 456-461. https://doi.org/10.1021/acs.estlett.9b00396

Kelly, K. E., Whitaker, J., Petty, A., Widmer, C., Dybwad, A., Sleeth, D., Martin, R., \& Butterfield, A. (2017). Ambient and laboratory evaluation of a low-cost particulate matter sensor. Environmental Pollution, 221, 491-500. https://doi.org/10.1016/j.envpol.2016.12.039

Koistinen, K. J., Edwards, R. D., Mathys, P., Ruuskanen, J., Künzli, N., \& Jantunen, M. J. (2004). Sources of fine particulate matter in personal exposures and residential indoor, residential outdoor and workplace microenvironments in the Helsinki phase of the EXPOLIS study. Scandinavian Journal of Work, Environment and Health, 20, 36-46.

Kulmala, M., Asmi, A., \& Pirjola, L. (1999). Indoor air aerosol model: The effect of outdoor air, filtration and ventilation on indoor concentrations. Atmospheric Environment, 33(14), 2133-2144. https://doi.org/10.1016/S1352-2310(99)00070-9

Li, Z., Che, W., Frey, H. C., Lau, A. K. H., \& Lin, C. (2017). Characterization of PM 2.5 exposure concentration in transport microenvironments using portable monitors. Environmental Pollution, 228, 433-442. https://doi.org/10.1016/j.envpol.2017.05.039 
Long, C. M., Suh, H. H., Catalano, P. J., \& Koutrakis, P. (2001). Using Time- and Size-Resolved Particulate Data To Quantify Indoor Penetration and Deposition Behavior. Environmental Science \& Technology, 35(10), 2089-2099. https://doi.org/10.1021/es001477d

Mehra, B. (2001). Bias in Qualitative Research: Voices from an Online Classroom. The Qualitative Report, 7(1), 1-19.

Minet, L., Liu, R., Valois, M.-F., Xu, J., Weichenthal, S., \& Hatzopoulou, M. (2018). Development and Comparison of Air Pollution Exposure Surfaces Derived from On-Road Mobile Monitoring and Short-Term Stationary Sidewalk Measurements. Environmental Science \& Technology, 52(6), 3512-3519. https://doi.org/10.1021/acs.est.7b05059

Özkaynak, H., Xue, J., Spengler, J., Wallace, L., Pellizzari, E., \& Jenkins, P. (1996). Personal exposure to airborne particles and metals: Results from the particle team study in Riverside, California. Journal of Exposure Analysis and Environmental Epidemiology, 6(1), 57-78.

Piedrahita, R., Kanyomse, E., Coffey, E., Xie, M., Hagar, Y., Alirigia, R., Agyei, F., Wiedinmyer, C., Dickinson, K. L., Oduro, A., \& Hannigan, M. (2017). Exposures to and origins of carbonaceous PM2.5 in a cookstove intervention in Northern Ghana. Science of The Total Environment, 576, 178-192. https://doi.org/10.1016/j.scitotenv.2016.10.069

QGIS Development Team. (2019). QGIS User Guide—Release 3.4.

Quinn, C., Miller-Lionberg, D. D., Klunder, K. J., Kwon, J., Noth, E. M., Mehaffy, J., Leith, D., Magzamen, S., Hammond, S. K., Henry, C. S., \& Volckens, J. (2018). Personal Exposure to PM 2.5 Black Carbon and Aerosol Oxidative Potential using an Automated Microenvironmental Aerosol Sampler (AMAS). Environmental Science \& Technology, 52(19), 11267-11275. https://doi.org/10.1021/acs.est.8b02992 
451 Salmon, M., Milà, C., Bhogadi, S., Addanki, S., Madhira, P., Muddepaka, N., Mora, A., Sanchez, M., Kinra, S., Sreekanth, V., Doherty, A., Marshall, J. D., \& Tonne, C. (2018). Wearable

Slezakova, K., Castro, D., Pereira, M. C., Morais, S., Delerue-Matos, C., \& Alvim-Ferraz, M. C.

Spencer-Hwang, R., Soret, S., Valladares, J., Torres, X., Pasco-Rubio, M., Dougherty, M., Kim, W., \& Montgomery, S. (2016). Strategic Partnerships for Change in an Environmental Justice Community: The ENRRICH Study. Progress in Community Health Partnerships: Research, Education, and Action, 10(4), 541-550. https://doi.org/10.1353/cpr.2016.0062

Thomas, K. W., Pellizzari, E. D., Clayton, C. A., Whitaker, D. A., Shores, R. C., Spengler, J., Ozkaynak, H., Froehlich, S. E., \& Wallace, L. A. (1993). Particle Total Exposure Assessment Methodology (PTEAM) 1990 study: Method performance and data quality for personal, indoor, and outdoor monitoring. Journal of Exposure Analysis and Environmental Epidemiology, 3(2), 203-226. 
472 Wallace, L. (1996). Indoor Particles: A Review. Journal of the Air \& Waste Management $473 \quad$ Association, 46(2), 98-126. https://doi.org/10.1080/10473289.1996.10467451

474 Yu, H., Russell, A., Mulholland, J., \& Huang, Z. (2018). Using cell phone location to assess 475 misclassification errors in air pollution exposure estimation. Environmental Pollution, 233, 476 261-266. https://doi.org/10.1016/j.envpol.2017.10.077

477 Yu, X., Stuart, A. L., Liu, Y., Ivey, C. E., Russell, A. G., Kan, H., Henneman, L. R. F., Sarnat, S. E., Hasan, S., Sadmani, A., Yang, X., \& Yu, H. (2019). On the accuracy and potential of Google Maps location history data to characterize individual mobility for air pollution health studies. Environmental Pollution, 252, 924-930. \& Carlson, D. E. (2018). Field evaluation of low-cost particulate matter sensors in highand low-concentration environments. Atmospheric Measurement Techniques, 11(8), 48234846. https://doi.org/10.5194/amt-11-4823-2018 